\title{
FOTOGRAFIAS EM DISCURSO: AS FUNÇÕES DA ESCOLA EM FOCO
}

\author{
PHOTOGRAPHS IN DISCOURSE: THE FUNCTIONS OF THE SCHOOL UNDER FOCUS
}

\author{
FOTOGRAFÍAS EN LOS DISCURSOS: LAS FUNCIONES DE LA ESCUELA EN FOCO
}

\section{SCHWERTNER, Suzana Feldens ${ }^{1}$}

\section{RESUMO}

Como os estudantes concluintes do Ensino Médio e Fundamental entendem as funções da escola hoje? O que esta instituição produz de sentidos aos olhares jovens? Estas foram as perguntais iniciais que guiaram os grupos focais constituídos pelos estudantes participantes da pesquisa "A escola e as novas configurações da contemporaneidade: a voz de estudantes concluintes do Ensino Médio e Fundamental" (MCTI/CNpq/Universal/2014), realizada entre 2015 e 2016, no interior do Rio Grande do Sul. Os jovens foram convidados a produzir fotografias, acompanhadas de uma legenda, que apresentassem as funções da escola na atualidade. Partindo dos estudos de Sibilia (2012), Masschelein e Simons (2014), o marco teórico da investigação perpassa as noções de discurso e suas relações de saber-poder (FOUCAULT, 2002; 2012; 2015), além de envolver uma discussão sobre fotografia (BARTHES, 1984; DUBOIS, 2012) e suas potencialidades na pesquisa em educação. Os resultados apontam para as funções pedagógicas, políticas e sociais que a escola exerce na contemporaneidade, sem deixar de mencionar as possibilidades de expressão que ela também potencializa.

Palavras-chave: Fotografia. Escola. Juventude.

\section{ABSTRACT}

How do students attending the last grade of Basic School and High School understand the functions of the school today? Which meanings does this institution produce from the students' view? These were the starting questions that guided the focus groups of students participating in this research, which was carried out in 2015 and 2016 in the countryside of the state of Rio Grande do Sul. The youths were asked to produce photographs accompanied by subtitles presenting the current functions of the school. Grounded on studies by Sibilia (2012), Masschelein and Simons (2014), the theoretical references of this investigation comprehended the notions of discourse and its knowledge-power relations (FOUCAULT, 2002; 2012; 2015), besides including a discussion about photography (BARTHES, 1984; DUBOIS, 2012) and its potentialities in research in education. The results pointed out the pedagogical, political and social functions performed by the school in contemporaneity, also mentioning the possibilities of expression that it potentiates.

Keywords: Pphotography. School. Youth.

\section{RESUMEN}

¿Cómo entienden las funciones de la escuela de hoy los estudiantes que finalizan el Enseño Medio Fundamental? ¿Qué sentido brinda ésta institución a las miradas jóvenes? Éstas fueron las primeras preguntas que guiaron a los grupos focales constituidos por los estudiantes que participaron de la investigación, realizada entre 2015 y 2016, en el interior de Rio Grande do Sul. Los jóvenes fueron invitados a producir fotografías acompañadas de un título donde presentasen las funciones de la escuela en la actualidad. Partiendo de los estudios de Sibila (2012), Masschelein y Simons (2014), el marco teórico de la investigación recorre las nociones de los discursos y sus relaciones de saber-poder (FOUCAULT, 2002; 2012; 2015), además de envolver una discusión sobre fotografía (BARTHES, 1984; DUBOIS, 2012) y sus potencialidades en la investigación sobre educación. Los resultados apuntan a las funciones pedagógicas, políticas y sociales que la escuela ejerce en la contemporaneidad, sin dejar de mencionar las posibilidades de expresión que ésta también potencializa.

Palabras clave: Fotografía. Escuela. Juventud.

\footnotetext{
1 Universidade do Vale do Taquari - Univates - Lajeado - Rio Grande do Sul - Brasil
} 


\section{INTRODUÇÃO}

O presente trabalho parte de um projeto de pesquisa (Edital Universal 14/2014) vinculado ao Mestrado em Ensino da Univates e articulada aos grupos de pesquisa Juventudes, Imagem e Educação (JImE) e Currículo, Espaço, Movimento (CEM), ambos do Diretório CNPq. Busca incentivar a discussão e a produção fotográfica de jovens estudantes acerca das funções da escola na contemporaneidade. Parte do pressuposto de que os estudantes compõem o universo escolar como protagonistas e merecem espaço para discutir sobre sua vida no universo escolar, bem como seu processo de ensino e de aprendizagem.

De que modo os estudantes concluintes do Ensino Médio e Fundamental - $3^{\circ}$ e $9^{\circ}$ ano, respectivamente - entendem as funções da escola hoje? O que esta instituição produz de sentidos aos olhares jovens? Como eles percebem a organização dos saberes escolares? E de que modo a escola contribui em sua formação? Estas foram as perguntas iniciais que guiaram os grupos focais constituídos pelos estudantes participantes da pesquisa, realizada entre 2015 e 2016 (e que segue em andamento até o final de 2017). Juntamente com o processo de discutir coletivamente sobre a escola, suas funções e efeitos em suas vidas, os jovens também foram convocados a produzir imagens fotográficas que pudessem responder a esta provocação. Em seguida, realizaram um debate coletivo por meio de foto elicitação (BANKS, 2009; 2001), que instigou os estudantes a ampliar o olhar por meio das fotografias dos colegas.

O trabalho aqui desenvolvido toma como objeto de atenção uma seleção das fotografias produzidas pelos estudantes participantes da pesquisa entre 2015 e 2016. Na continuidade da escrita, o trabalho apresenta os marcos teóricos que fundamentam a investigação, com especial ênfase às problematizações que circundam as configurações da escola na atualidade, sem deixar de destacar elementos constituintes das imagens fotográficas, tópico que neste artigo articula educação e comunicação.

\section{AMPLIANDO O OLHAR: DISCUSSÕES SOBRE A ESCOLA}

Falar sobre a escola parece ser uma necessidade para todos: é por meio da escola que se aprende, que se constitui cidadãos, que se prepara para o trabalho, que se constrói o futuro de uma nação. Em todos as campanhas (sejam elas políticas, educacionais, culturais), a escola e sua contribuição na vida de crianças e jovens parece exercer lugar de destaque. Contudo, nem sempre é esta a prioridade dos investimentos governamentais. A mídia e suas muitas formas de veiculação (jornal impresso e online, televisão, rádio, websites), apresenta cotidianamente reportagens, imagens, entrevistas com especialistas (na maioria das vezes, administradores e empresários) que discutem suas opiniões acerca dos problemas em torno da educação.

Talvez, conforme nos ensinou Michel Foucault em História da Sexualidade (1988), se trate de um discurso para muito ainda se falar e pouco dizer, criando assim uma "aura de mistério" sobre o 
tema. Ao estudar sobre a explosão discursiva em torno da sexualidade a partir do século XVIII, Foucault demonstrou o quanto as restrições sobre o sexo (as práticas, as proibições, as manifestações) serviram para ampliar ainda mais seus contornos, contribuindo para uma "fermentação discursiva".

O que se propõe, junto aos "murmúrios" ruidosos (FISCHER, 2002) que constituem as condições de emergência dos discursos sobre educação na contemporaneidade, é pensar sobre os desencaixes da escola (TRAVERSINI, 2010), sua inadequação em relação às transformações sociais (BARROSO, 2008) e aos corpos e subjetividades dos estudantes (SIBILIA, 2012). Ainda, busca-se problematizar o espaço da escola como um lugar de "conveniência" (COSTA; MOMO, 2009), que ainda centraliza narrativas redentoras (FISCHMAN; DIAZ, 2013).

Apontamos aqui para a crise da escola moderna e os desafios da escola contemporânea, bem como suas interfaces com a formação docente e o espaço destinado aos estudantes neste processo. Como pensar o lugar da escola em um tempo em que os espaços de aprender têm se multiplicado e que a crise da autoridade docente tem apresentado uma série de novas perguntas ao universo escolar? (FISCHER, 2004; DUFOUR, 2005). Como pensar a escola organizada em torno de um tempo livre, dedicado a abrir o olhar para o mundo, trazer o mundo para a vida (MASSCHELEIN; SIMONS, 2014)?

Entendemos os espaços educativos não apenas constituídos por estruturas físicas e compostas pela junção de professores, gestores e estudantes, tendo como função o exercício da educação formal. Compreende-se instituição escolar a partir de autores como Júlio Groppa Aquino (1996; 2000) e Marlene Guirado $(2004 ; 2010)$, os quais destacam não apenas sua função de organização dos sujeitos e suas práticas, mas enquanto espaço produtor de modos de subjetividade. Assim, a escola seria esse espaço produzido por um conjunto de práticas sociais que é proposta em meio a um exercício de poder entre diferentes atores institucionais em seu fazer cotidiano. $E$ uma instituição, dessa maneira, jamais deixa de ser atravessada pelo seu contexto histórico, político, econômico, cultural e social.

Talvez sejam estas também as articulações com as funções da escola na contemporaneidade: não esquecer seu caráter de envolvimento com o mundo que a cerca e que também solicita reconfigurações a todo momento. Como ressaltam Fischman e Diaz (2013), trata-se não de tomar as escolas por meio de uma narrativa redentora, mas compreende-las como espaços de aposta contínua, de comprometimento, "[...] lugares de possibilidade e atuação" (p. 510). Quais discursos sobre a escola percebemos na atualidade? O que é possível ver e entender, nesta determinada época, por meio do olhar dos jovens estudantes concluintes - que poucas vezes são chamados a falar e a contar sobre a escola? Até que ponto a escola possibilita pensar sobre as imagens que circulam em nosso cotidiano, trazê-las para o ambiente escolar e proporcionar espaço para discussão, problematização e, inclusive, para criação e produção? 


\section{MÍDIA E EDUCAÇÃO - IMAGENS E FOTOGRAFIA}

Conforme Fischman e Sales (2014), pesquisas sobre imagens na Educação ainda são escassas em estudos brasileiros. Os recursos visuais deveriam ser utilizados para aprimorar conhecimentos de educadores e pesquisadores sobre diferentes tópicos na pesquisa educacional, sejam aqueles tradicionalmente investigados ou mesmo temáticas mais recentes. Nosso papel como pesquisadores deveria incorporar criticamente "[...] a noção de questionamento e a reflexão daquilo que vemos e como estas imagens são construídas e reconstruídas por todos os participantes de um determinado projeto de pesquisa" (FISCHMAN, 2001, p. 32).

Parece ser cada vez mais necessário o estudo das imagens não apenas como mera ilustração, como aspecto secundário do pensamento, mas por aquilo que ela significa em si mesma, como discurso. Trata-se, pois, de produzir pensamento no espaço educacional a partir de elementos visuais aos quais nos lançamos cotidianamente - no caso desta pesquisa, sobre fotografias produzidas no ambiente escolar por jovens estudantes.

As fotografias, objeto de interesse e investigação para Walter Benjamin (1994), eram consideradas, à época, objetos de terceira categoria, os quais não mereciam estudos mais aprofundados. Porém, para o autor, as imagens possuíam uma prioridade primeira e carregariam consigo um potencial revolucionário. Enquanto objeto social, a fotografia, elemento de caráter político, apresenta traços de uma época, de uma cultura, dos hábitos de um povo, de seu comportamento. Somente a imagem, segundo Benjamin, teria o poder de desalienar, de fazer "acordar de um sonho" ao contrário dos ditos que circulam no senso comum sobre a disseminação de imagens na atualidade.

Roland Barthes (1984) solicita repensar o valor da imagem em contraposição ao valor atribuído ao escrito. E pergunta-se sobre a classificação das imagens fotográficas, destacando que a foto também gostaria de ser "[...] gorda, tão segura, tão nobre quanto um signo" (BARTHES, 1984, p.16). Conforme Barthes, a fotografia é investida de uma autonomia e necessita ser pensada como um objeto particular, diferenciado, com sua metodologia própria.

Pensar sobre imagens fotográficas torna-se um trabalho importante para o pesquisador em educação que busca compreender os jogos de verdade de uma época, de investigar a produção de subjetividades em um determinado contexto. Segundo Fischman (2006, p.85), a fotografia, em seu potencial, é capaz de "[...] resgatar recordações potentes, tensões significativas e contraditórias que só o olhar - qualquer olhar - pode tornar visível desde que sempre se considere sua capacidade de estruturar e des-estruturar". Conforme Achutti (1995), é preciso atentar para a relação entre o olhar (singular) que é apreendido e está em conexão com determinada conjuntura social, por meio das imagens:

O olhar é aprendido, é treinado de forma articulada com outros olhares. O olhar não é individual, ele é determinado social e conjunturalmente. E é em função do tipo de olhar de uma dada época que são determinados os tipos de imagens e de que forma as pessoas se relacionam com elas. (p. 432). 
Para Walter Benjamin (1994), a fotografia marca e paralisa um instante, mortifica algo que, na hora do clique/toque, perde a vida para além do instante; a cena possui algo para nos dizer, convoca a pensar mais além: convoca-nos a vivificar aquilo que foi paralisado. Acreditamos que é também por este caminho que a Educação e a pesquisa por meio das imagens poderiam se apropriar da fotografia, convocando a um pensamento sobre as funções e os sentidos da escola para os jovens estudantes. $O$ que se visibiliza - e se torna possível murmurar - sobre a escola na contemporaneidade por meio de fotografias produzidas por um grupo de estudantes concluintes do Ensino Médio e Fundamental?

\section{A ESCOLA NA MIRA DOS ESTUDANTES}

Esta investigação, do tipo qualitativa e exploratória, está organizada por meio de grupos focais de discussão (BARBOUR, 2009; GIL, 2009; GATTI, 2005). Para Gil, no decorrer da técnica do grupo focal "[...] os participantes interagem entre si num processo de discussão que é observado e registrado pelo moderador, que é alguém integrado ao grupo" (p. 84). Os grupos focais acontecem em torno de duas questões principais, que versam sobre as funções da escola na atualidade e sobre o modo como a escola organiza os saberes para os estudantes.

Associada ao trabalho com grupos focais, a produção de imagens e posterior discussão coletiva das fotografias entre os estudantes é tomada como matéria-prima da pesquisa. A foto elicitação é um recurso trabalhado com crianças e jovens para auxiliar no processo de participação e compartilhamento de experiências e um instrumento interessante para a discussão de temáticas contemporâneas (WOODGATE et al., 2017; TORRE; MURPHY, 2015; BANKS, 2001; WANG et al., 1998). Trata-se de um modo de pesquisa mais participativo, que possibilita aos sujeitos selecionar aspectos relevantes de sua vida (escolar, no caso desta investigação) e produzir pensamentos e narrativas por meio das imagens. Trabalhos de pesquisa que se apropriam desta metodologia são escassos não apenas no contexto brasileiro, mas em nível internacional (TORRE; MURPHY, 2015).

Pensar sobre as fotografias como acontecimento também é um dos motes desta pesquisa. Fotografia, neste caso, como produção que expressa e produz sentidos, desejos e questionamentos sobre o universo escolar e que articula o mundo interno e externo daquele que a elabora:

Fotografar é um movimento de expressão e produção de sentidos que se faz na relação entre os mundos internos e externos. E nesta dança entre a informação e a imaginação, entre o registro e a invenção que se dá no ato de fotografar buscamos compreender por onde caminham os significados dados aos pequenos acontecimentos dos nossos ricos e conflituosos cotidianos. (WUNDER, 2006, p.11).

Paralelamente ao ato de criação e produção das imagens, há que se atentar para a processualidade deste ato e daquilo que o extrapola, para a produção de pensamentos a partir das imagens, para a enunciação que se segue a ela; enfim, para aquilo que Dubois (2012) tomou como "enunciado fotográfico": 
A fotografia, em suma, como inseparável de toda a sua enunciação, como experiência de imagem, como objeto totalmente pragmático. Vê-se com isso o quanto esse meio mecânico, ótico-químico, pretensamente objetivo, do qual se disse tantas vezes no plano filosófico que ele se efetuava "na ausência do homem", implica de fato ontologicamente a questão do sujeito, e mais especialmente do sujeito em processo. (p. 15)

A organização da investigação está pautada por quatro encontros, com a duração de aproximadamente 45 minutos: o primeiro e o segundo encontros têm por finalidade discutir as funções da escola na contemporaneidade e o modo como a instituição escolar organiza os conhecimentos. Utiliza-se um gravador eletrônico para registrar as interações entre os participantes e os encontros são mediados por uma dupla de coordenadores da pesquisa. O terceiro encontro é marcado pela produção da fotografia, ambientada no espaço da escola e que aparece acompanhada de uma legenda, organizada pelos participantes. No quarto e último encontro, os estudantes visualizam coletivamente as imagens e discutem sobre suas fotografias. Nos anos de 2015 e 2016, os encontros foram realizados em duas escolas de um município no interior do Rio Grande do Sul (Brasil), uma instituição de ensino privado e outra de ensino público, contando com a participação de 82 estudantes concluintes do Ensino Fundamental e Médio, com idades que variaram entre 14 e 18 anos.

Os dados produzidos são problematizados por meio da análise de discurso foucaultiana, levando em conta que não se trata de buscar "a verdade escondida" no relato dos estudantes e sim da noção de que os discursos não ocorrem fora de uma ordem mais ampla, e sim num campo de possibilidades que permite que esses ditos possam funcionar como verdadeiros (FOUCAULT, 2015; 2002). Assim, os discursos não constituem apenas uma forma de falar, de dizer algo, mas uma prática que toma corpo nas instituições, produzindo sujeitos: aquilo que se pode ver e dizer em certo tempo e lugar. No olhar de Fischer (2012), trata-se de um trabalho minucioso que é exigido do pesquisador, na medida em que busca "[...] descrever os diversos modos pelos quais o social é tecido discursivamente" (p. 135).

Para este artigo, limitamos a análise ao terceiro encontro: aquele marcado pela produção da fotografia e a elaboração da legenda de cada um dos participantes. Os estudantes utilizaram máquinas fotográficas oferecidas pelo grupo de pesquisa e, em um período de 45 minutos, produziram as imagens a partir de algumas orientações quanto ao uso da máquina e aos cuidados éticos em relação à captação de imagens de pessoas que não faziam parte da pesquisa. Vale destacar que os responsáveis pelos participantes da pesquisa assinaram um Termo de Consentimento Livre e Esclarecido, que apresentou os objetivos da pesquisa; além disso, os próprios estudantes assinaram um Termo de Assentimento, concordando com sua participação da investigação.

Selecionamos seis imagens das 82 produzidas pelos participantes: o critério de seleção envolveu os elementos mais foram fotografados pelos estudantes, além de títulos de legendas que abarcaram aspectos das funções da escola mais apresentados nas imagens. Elas serão exibidas no texto seguidas da legenda e da turma do estudante.

Para a análise do material, partimos do pressuposto indicado por Barthes (1984; 1990), de que a fotografia instaura uma nova forma de olhar e nos propomos a "aventurar" as imagens. Fotografias 
em discurso, que nos contam sobre o desejo de informações que temos diante das imagens (KUBRUSLY, 1991): momentos antes e após o instante fotografado, as pessoas e objetos presentes na fotografia, o lugar, a época. Mas também não deixamos de atentar para aquilo que Peixoto (1992) afirmou como as possibilidades de a fotografia mostrar algo que não foi, inicialmente, visado por aquele que produziu a imagem, "[...] algo que ali se imiscuiu, sem que o fotógrafo tenha planejado" (p. 306). Enfim, as condições de emergência deste "discurso fotografado".

\section{FOTOGRAFIAS EM DISCURSO}

Nas 82 imagens produzidas pelos estudantes de $9^{\circ}$ ano do Ensino Fundamental e $3^{\circ}$ ano do Ensino Médio, um elemento chama logo atenção: os livros estão presentes em 20 das fotografias. Elemento tradicional da escola, instrumento pedagógico essencial, ele foi lembrado e ressaltado pelos estudantes como "a base da aprendizagem". Jorge Ramos do Ó (2007) questiona a "mundividência" expressa pelo livro e marca sua hegemonia na escola: é neste objeto que se concentra a "verdade" e todas as tarefas escolares estão centradas no exercício da leitura.

Espaços como a sala de aula e a biblioteca tornaram-se cenários recorrentes para a apresentação deste elemento central para a realização de uma das funções primordiais da escola: a sua função pedagógica. Concomitantemente, é importante ressaltar que os livros fotografados pelos estudantes envolveram tanto os de cunho didático quanto os livros de literatura (nacional ou estrangeira) e o prazer de ler foi tão (ou até mais) ressaltado do que a leitura obrigatória ou do livro didático, pelo conjunto de participantes da pesquisa.

Na Fig. 1, um estudante de $9^{\circ}$ ano da escola pública apresenta seu canto preferido da escola (lugar organizado dentro da biblioteca), discutindo sobre o espaço mais informal destinado à leitura prazerosa - vemos ali, além de cadeiras mais confortáveis, um espaço com almofadas coloridas e um sofá acolchoado (este mesmo local foi fotografado outras vezes pelos estudantes desta escola, também para esta pesquisa): 
Figura 1: O saber da leitura

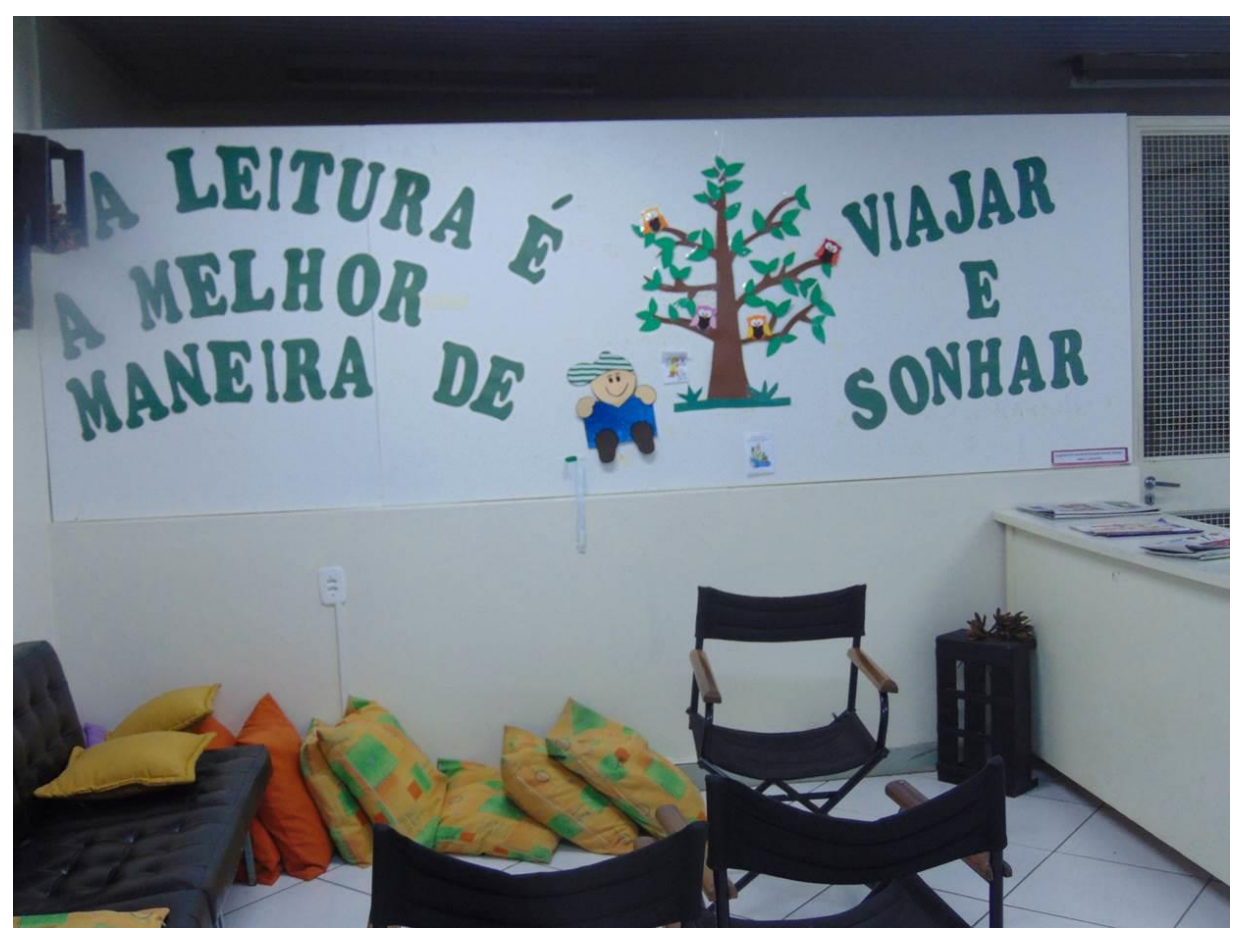

Fonte: Estudante $9^{\circ}$ ano (2015)

A fotografia também nos convida à leitura: a presença do cartaz (outro elemento característico da escola) toma conta de um espaço grande da foto e ressalta os aspectos da imaginação presente no ato de ler. Entendemos que não se trata da sala de aula, mas sim de um outro ambiente preparado para acolher a leitura e os leitores: a biblioteca, outro espaço bastante fotografado pelos participantes da pesquisa, durante os dois anos de realização do projeto.

A Fig. 2, diferentemente da anterior, nos apresenta um espaço aberto: rapidamente nos ambientamos no pátio escolar, ambiente colorido e que remete aos brinquedos que visualizamos no enquadramento proposto pelo estudante concluinte do Ensino Médio da instituição de ensino privado. Em primeiro plano, a imagem de duas gangorras (uma azul e outra vermelha), acopladas em uma mesma estrutura de base amarela. Da forma como foi composta a imagem, os dois elementos principais (as gangorras) se apresentam como os pratos de uma balança desequilibrados, revelando que um se sobrepõe ao outro. Na legenda, buscamos a articulação proposta pelo estudante-fotógrafo em seu entendimento sobre a função da escola: 
Figura 2: Passar o conhecimento e se relacionar entre as pessoas é um dever igual da escola

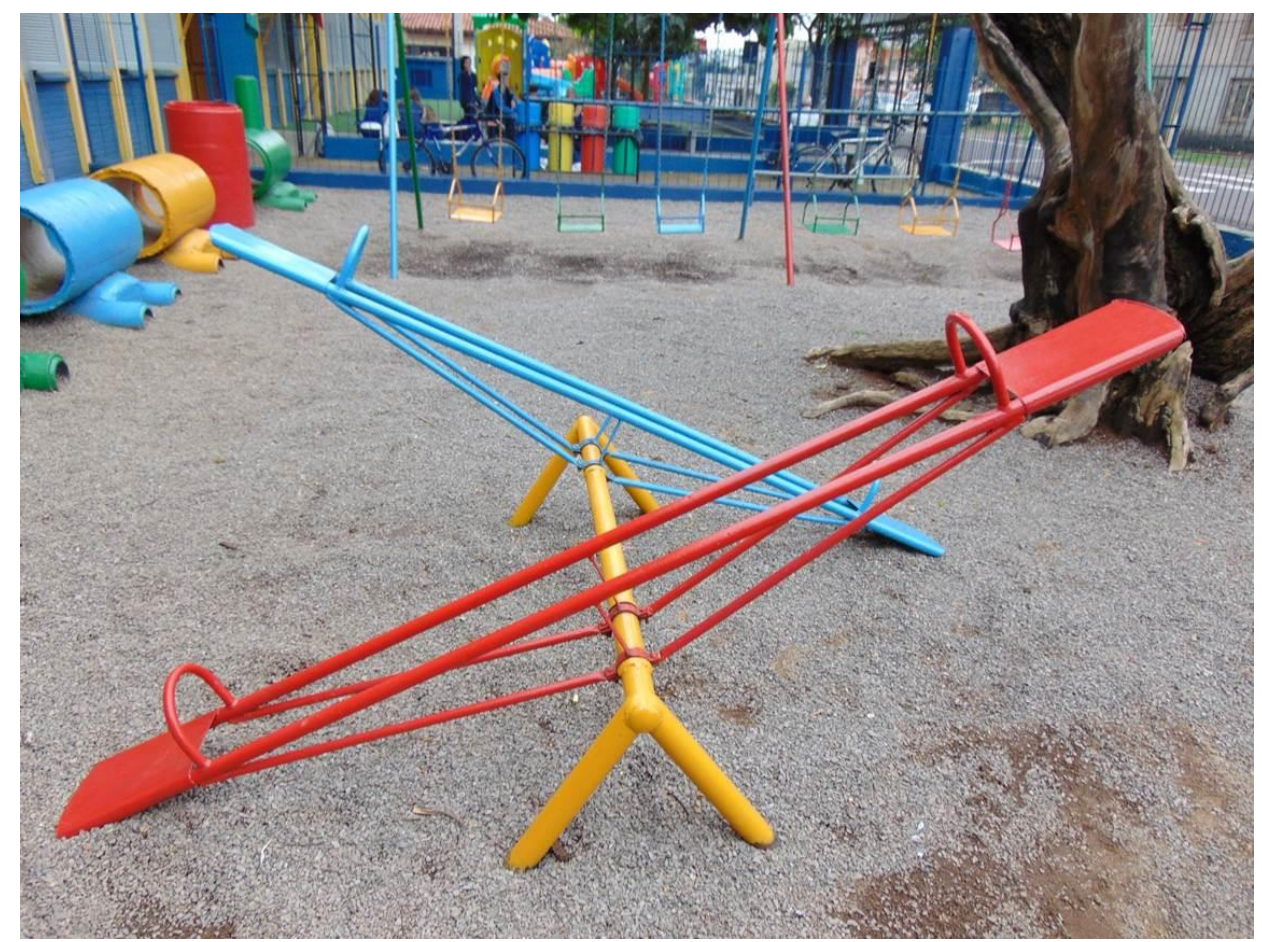

Fonte: Estudante $3^{\circ}$ ano (2015)

Aqui, a escola ainda é entendida como aquela que "passa conhecimento", que transmite o conhecimento e que esta função - nos parece, a mais saliente, ou aquela que parece ter um maior valor - se sobrepõe à função de socialização da escola, destacada pelo estudante como "se relacionar entre as pessoas". O jovem parece ressaltar que este é também um "dever" da escola para além do pedagógico: a função social é de intensa importância no olhar dos estudantes. Que tempo esta escola deveria dedicar ao conhecimento e às relações sociais que ali se desenrolam? De que é feito o tempo escolar?

Masschelein e Simons (2014) enfatizam que o tempo escolar seria aquele destinado ao tempo livre e indeterminado, "[...] que permite alguém se desenvolver como um indivíduo e como um cidadão, isento de quaisquer obrigações específicas relacionadas ao trabalho, familiares ou sociais" (p. 97). Para além de ser orientada por objetivos e prover direção ou destino, a educação não consiste em dizer o que os estudantes devem fazer mas envolve "[...] transformar o mundo (coisas, palavras, práticas) em algo que fala com eles" (p. 98). O tempo livre ressaltado pelos autores está pautado por um tempo direcionado para "[...] prestar atenção ao mundo, para respeitar, para estar presente, para encontrar, para aprender e para descobrir" (p. 98). Trata-se, portanto, de um tempo livre para aprender, conhecer, explorar - seja os conteúdos, seja as relações entre as pessoas que ali estão, seja a articulação entre ambos. 
Figura 3: Acredito que estamos na escola para, além de aprender, saber respeitar o outro

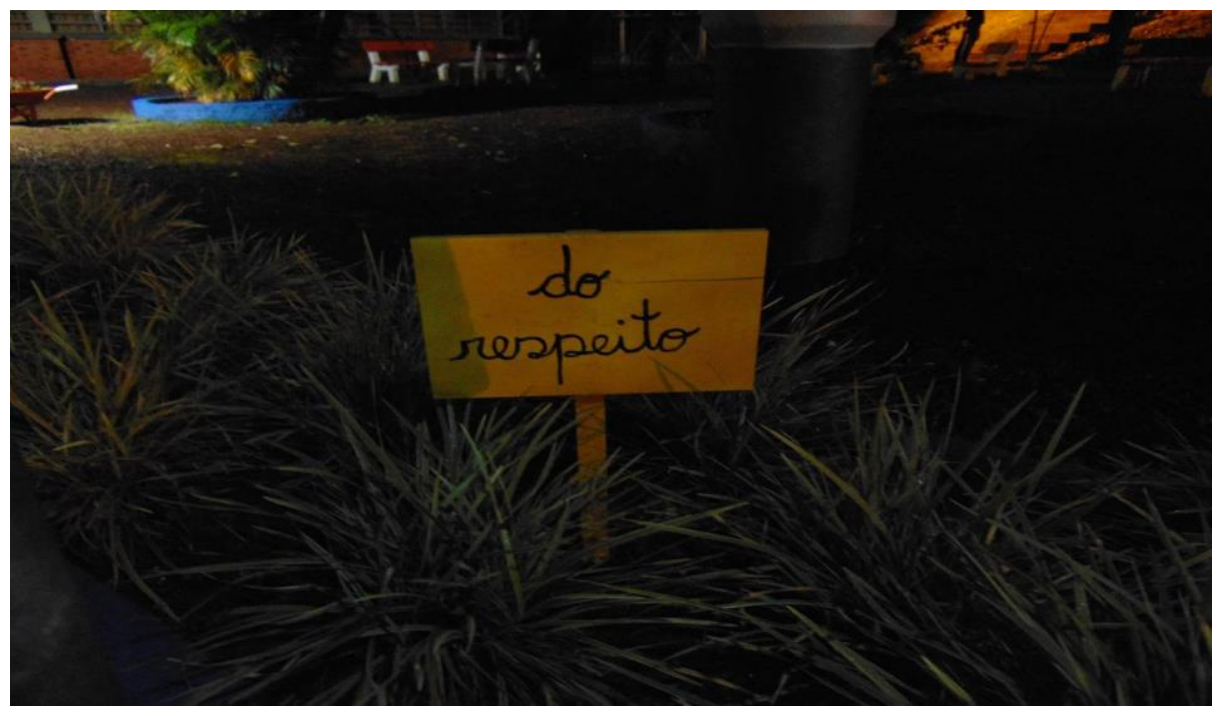

Fonte: Estudante $3^{\circ}$ ano (2015)

As funções sociais da escola aparecem destacadas em ambas imagens (Fig. 2 e 3): o encontro com os outros no espaço da escola - muitas vezes, o primeiro espaço após o ambiente familiar em que vão conviver. $\mathrm{Na}$ imagem 3 , a fotografia prende nossa atenção pela força da placa incrustada na terra, bem ao centro da imagem, talvez nos convocando a pensar sobre este tema tão pungente - não apenas na escola, mas especialmente nela, em um tempo marcado pelo desrespeito, pela desvalorização do ser humano, pautado pelo desencontro.

A fotografia é escura - foi produzida por estudante de uma turma de terceiro ano do turno da noite da escola pública - e vemos ao fundo que se trata de um espaço de pátio da escola. Há uma tênue iluminação na placa, com a palavra "do respeito" escrita em letra cursiva, outra característica do universo escolar: é ali que se aprende a escrever "com a letra emendada", elemento já tão pouco utilizado em nosso cotidiano regido por letras bastões e informatizadas. Há algo ali do respeito a este modo de produção escrita (ainda que parcamente iluminado), há algo ali que parece também nos remeter ao humano que vive neste espaço.

Interessante perceber que em ambas legendas que acompanham as imagens (Fig. 2 e 3), não é esquecida a menção à função pedagógica da escola ("conteúdos" e "aprender", respectivamente). Contudo, seu aspecto social é valorizado e destacado como "dever igual" da escola.

Vale destacar que esta placa fotografada se insere no espaço daquela escola compondo com uma "trilha" de outras placas semelhantes, que apresentam diferentes palavras para aqueles que adentram a escola. No momento de visualização coletiva, muitos estudantes se questionaram onde estavam estas placas que nunca tinham percebido; outros se lembravam de tais placas, mas não conseguiam lembrar exatamente de sua posição e nem tinham pensado nelas como uma composição 
de frases. Evgen Bavcar (2001), fotógrafo esloveno, nos fala da importância em atentar a detalhes por meio das imagens, de perceber novas ideias em velhas fotos, da multiplicação do olhar que elas proporcionam. Afirma o estudioso que precisamos levar em conta "[...] detalhes de aparência insignificantes, mas que, apesar de tudo, existem e dão uma nova aura às figuras que já estamos habituados demais em olhar, a partir de uma perspectiva única" (BAVCAR, 2001, p. 30).

Perspectivas múltiplas. Eis o mote que nos leva à análise da próxima imagem selecionada. Descobrir o mundo passa a ser tarefa da escola, mas também daqueles que ali estão: a tão conhecida função de "formar cidadãos", acompanha muito proximamente a função pedagógica da escola quando não se separam. A fotografia foi realizada em um espaço externo, durante o dia, por uma das estudantes da escola particular:

Figura 4: Escola é descobrir o mundo

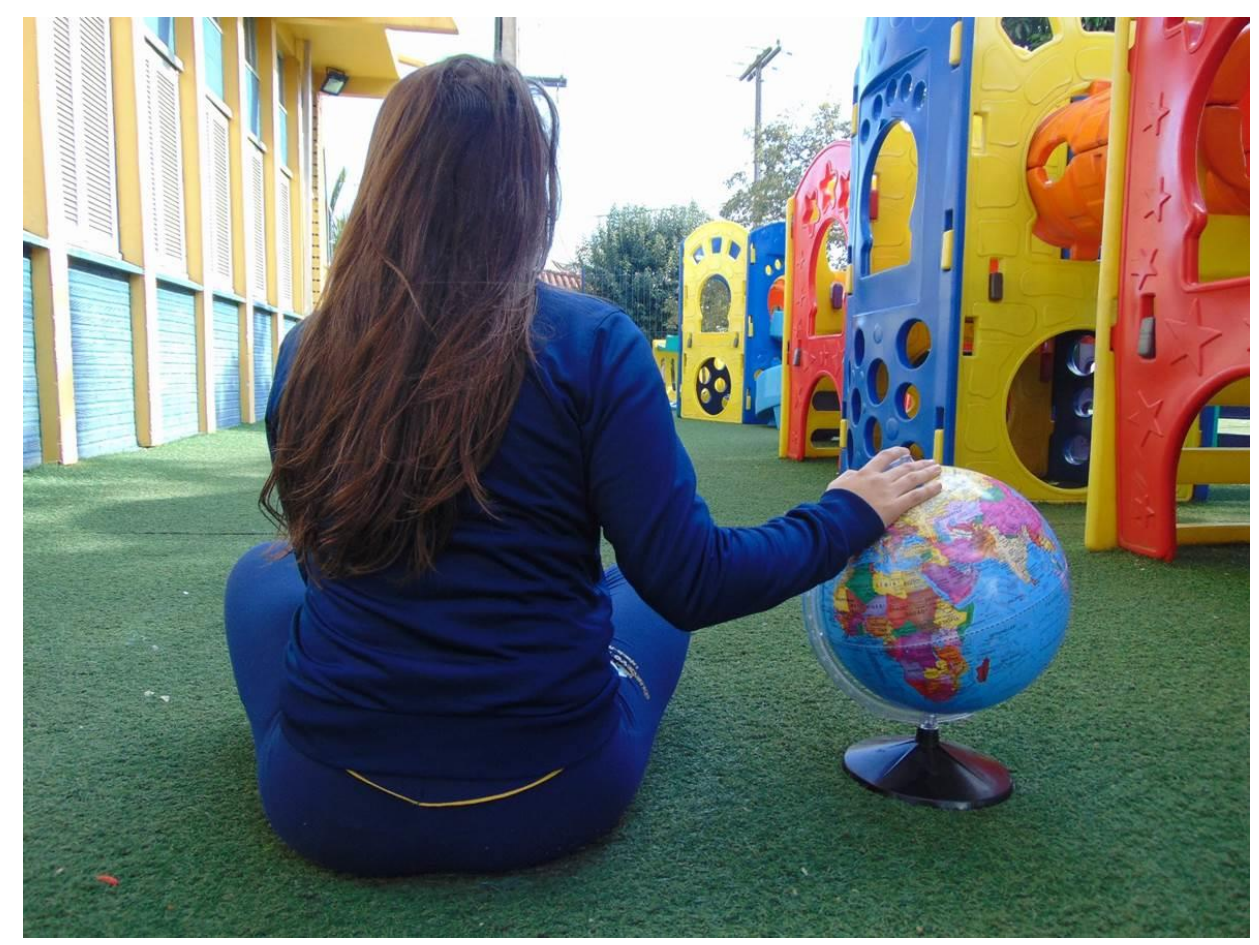

Fonte: Estudante $9^{\circ}$ ano (2016)

A imagem 4 nos apresenta uma estudante, de costas ao espectador, que olha para a frente, cabeça erguida, em perspectiva a uma linha do horizonte. É ladeada por duas linhas laterais, compostas pela parede da escola e por brinquedos de plástico multicoloridos. Sentada no chão, um gramado artificial que o cobre, tem ao seu lado um globo terrestre (outro elemento da educação formal que foi fotografado por diferentes estudantes durante a investigação). Com a mão direita, toca a parte superior do globo terrestre, que está deslocado de seu habitat natural em uma escola, a sala de aula. A função democrática e política da educação, como nos lembram Masschelein e Simons (2014), está alavancada pelo encontro de algo que eles denominam "dupla experiência do mundo", a saber: a 
noção de um bem compartilhado e a ideia de que o estudante pode, é capaz de algo novo (em oposição ao que ele "deve" fazer): "É a abertura de um mundo fora de nós mesmos e o envolvimento da criança ou do jovem nesse mundo compartilhado" (p. 99).

E quando apresentamos a imagem a seguir, em contraposição à proposta de "descobrir o mundo", o que vemos? De um espaço aberto, iluminado, colorido, com vistas ao horizonte, passamos para um ambiente escuro, iluminado artificialmente e com uma parede de tijolo ao final da vista. A fotografia foi produzida por um estudante do terceiro ano da escola pública (Fig. 5).

Figura 5: E podem me prender numa jaula. Porque sala de aula essa jaula vai virar.

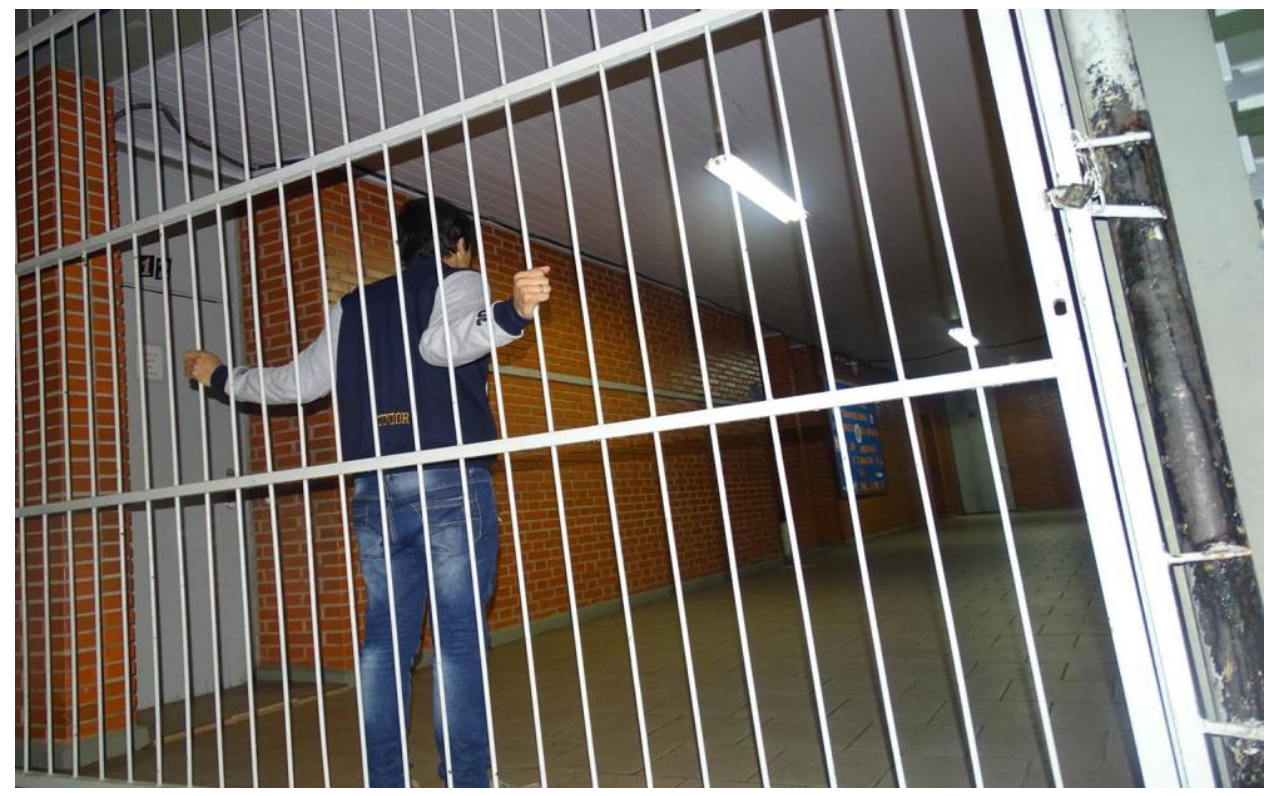

Fonte: Estudante $3^{\circ}$ ano (2016)

Os estudos foucaultianos sobre a relação entre saber e poder (FOUCAULT, 2002), sobre o cerceamento e disciplinamento de saberes e corpos (FOUCAULT, 2012) nas instituições (como a prisão, a indústria, o exército) podem ser aqui associados ao espaço da escola. A noção de uma sociedade disciplinar, em que os corpos são tornados dóceis e úteis, marcados por assimetrias e não reciprocidade é objeto de estudo do autor na obra Vigiar e Punir (FOUCAULT, 2012). A imagem apresenta uma visão gradeada da escola e que permite visualizar um estudante, de costas para quem olha para a foto, segurando-se nas grades de um portão, que por sua vez nos remete à prisão. A cena que o autor da imagem capturou parece colocar as duas instituições em jogo.

Contudo, não podemos nos esquecer de mencionar as condições de produção desta fotografia: o trabalho de pesquisa havia sido interrompido em virtude das ocupações realizadas nas escolas do Rio Grande do Sul entre maio e junho de 2016 e a produção das imagens foi retomada logo após o retorno às atividades da escola. Assim, podemos voltar à foto e perceber como ela provoca o olhar a confrontar-se com a legenda, apontando a "sala de aula" como uma resposta à "jaula". 
Cabe ressaltar que a estrofe de uma música foi utilizada pelo estudante concluinte do Ensino Médio para definir a legenda de sua imagem. "O trono do estudar", música produzida por Dani Black como apoio aos estudantes contra as medidas do governo estadual de São Paulo sobre a reorganização dos espaços escolares, em 2015, foi também parte integrante da fotografia por meio da legenda selecionada. Tal música foi regravada por 18 artistas brasileiros, entre eles Chico Buarque e Zélia Duncan, e divulgada na mídia em dezembro de 2015. Não se trata de entender unicamente a escola como uma prisão, mas justamente o seu oposto: a instituição escolar aparece aqui, na visão deste estudante, como aquela que permite apresentar uma resposta ao fato de ser aprisionado, "enjaulado". Não negamos, com isso, os elementos que apontam para o caráter disciplinador, ordenador, de docilização dos corpos que a instituição escolar ainda parece assumir; no entanto, é possível ressaltar também, levando em consideração o momento de produção da imagem e sua interlocução com a legenda, o caráter até mesmo transgressor da escola.

Outro aspecto importante a ressaltar nas imagens produzidas são os elementos que apontam para especificidades da vida jovem: a força das amizades construídas na escola (muito destacadas nas fotografias e nos debates coletivos pelos estudantes, especialmente aqueles que estão concluindo o Ensino Médio), o momento de questionar-se sobre a vida profissional e sobre "quem eu sou" - e, por sua vez, a saída da escola, o autoconhecimento que se realiza sempre por meio das parcerias nesta instituição. Aqui, apresentamos uma fotografia (produzida por uma estudante do $9^{\circ}$ ano da instituição de ensino privado - Fig. 6) que remete à necessidade de expressão dos jovens e o modo como eles entendem que tal expressão é possível na escola: por meio da arte e das manifestações artísticas, que acontecem no espaço externo, aberto, mais informal, da escola.

Figura 6: Expressar-se através da arte para se fazer entender

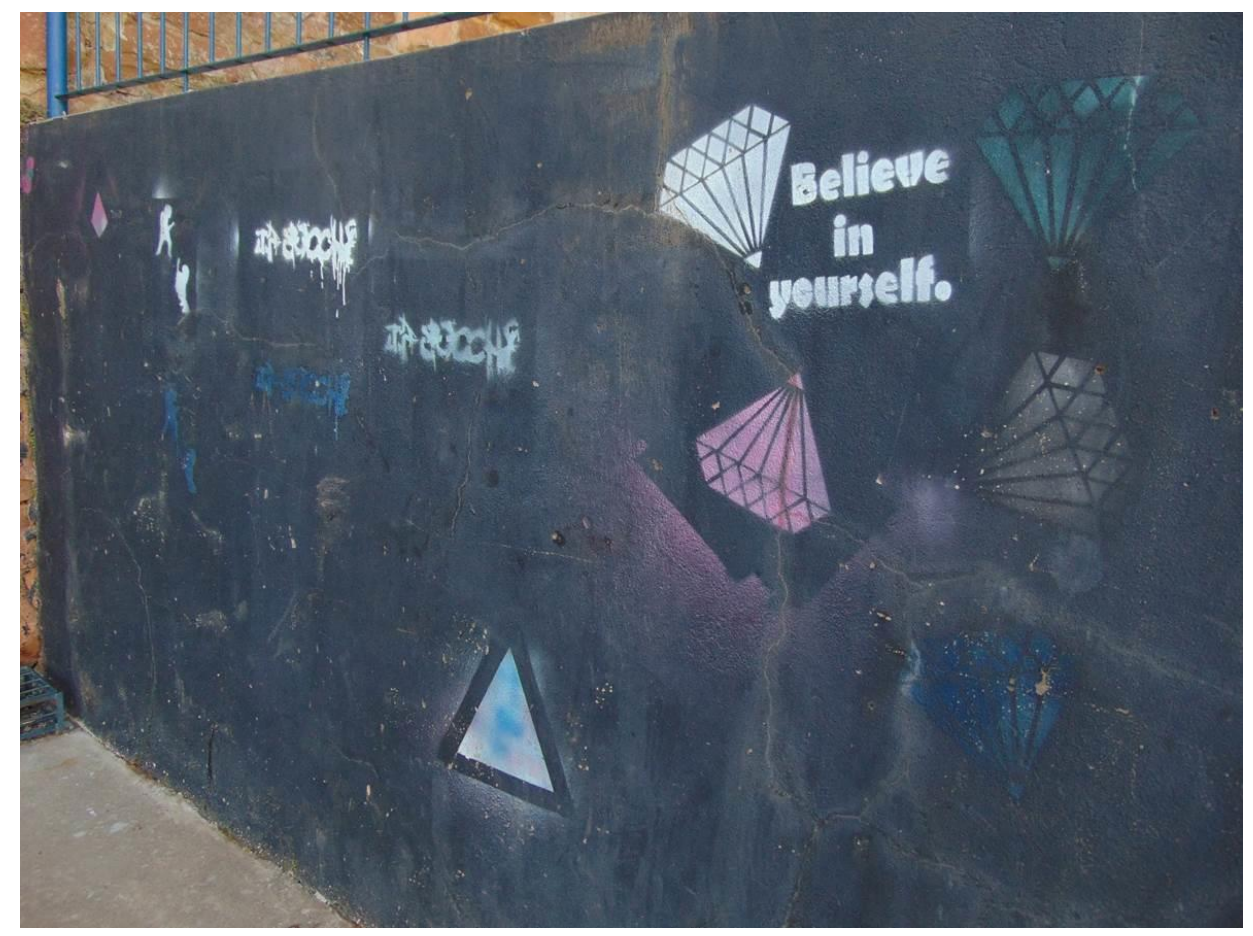


Juventude: tempo sombrio, espaço incerto, corpo desmedido, desentendimento, imagem, linguagem. Eles falam outra língua? Estrangeiros na própria terra, os jovens também demonstram sua necessidade de expressão no espaço da escola - e a arte parece ser a melhor linguagem, aquela capaz de produzir nos jovens estudantes a possibilidade de acreditarem em si mesmos. Uma parede da escola, eles nos dizem, pode apresentar isso - ao lado de desenhos pré-moldados, grafites, escritos: possibilidades diferentes de expressão. "Acreditar em si mesmo" parece ser "o chamado" para este período tão conturbado e tão intenso - e a parede da escola pode ajudar a manifestar e a contribuir neste processo: ela é parte constituinte dessa vida jovem que ali se desdobra e vivencia uma série de desventuras.

\section{PENSAR A ESCOLA POR MEIO DE OLHARES DE JOVENS ESTUDANTES}

O acesso às imagens, que parece hoje tão saturado e até mesmo banalizado, toma outros rumos quando se solicita aos estudantes a produção de fotografias por meio de câmeras destinadas a esta função, em um projeto que busca conversar - e olhar - acerca da escola. O interesse, a disposição, a admiração, a organização e a seriedade com que os jovens se envolveram nas atividades de pesquisa (desde os debates e as controvérsias que ali se estabeleceram, a elaboração das cenas fotografadas, o trabalho em conjunto com os colegas) comoveu as pesquisadoras.

Estudantes de 14 a 18 anos se comprometeram com a investigação e ficaram admirados com as suas produções, além de se empolgarem com a proposta de falar sobre a escola, de serem escutados, de pensarem em conjunto sobre aquilo que vivenciam durante tanto tempo de suas vidas. Olhar por meio das câmeras o espaço escolar e ali elaborar uma imagem que apresentasse os sentidos e as funções da escola aproximou estudantes de seus colegas e de outros participantes daquele espaço. Um olhar que ativou outros olhares, que estimulou o exercício criativo dos jovens estudantes.

Entregar-se à escola e pensar sobre ela a partir de um outro lugar, como produtores de imagem e debatedores sobre os processos que ali acontecem, ativou os olhares para aquilo que é cotidiano, para o caminho que todos fazem no espaço da escola sem perceber, para uma certa nostalgia que esta instituição evoca, para a promessa de apresentação de um mundo e sua descoberta, para os percalços e normatizações que ela apresenta àqueles que concluem os doze anos da Educação Básica. Não deixaram, os estudantes, de olhar para a disciplina que se faz presente com bastante evidência na escola, esta máquina que ainda aparece como desadaptada aos corpos e subjetividades dos jovens na atualidade (SIBILIA, 2012).

Percebemos ali também, em meio a este processo de pensar sobre a escola, momentos de captura destes estudantes que já se adaptaram às normas, modelos, comportamentos e exigências 
produzidas pela instituição escolar - e reproduzidas por eles em algumas imagens. O livro como "base do conhecimento" e o "saber da leitura", amplamente legitimado na aprendizagem formal, foi alvo de olhares e reproduziu um enunciado há muito disseminado como verdade para as funções da escola. $O$ disciplinamento, a ordenação, o aprisionamento dos corpos também foi destacado, juntamente com a proposta de pensar a escola como possibilidade de expressão e manifestação por meio da arte.

Ressalta-se, ao final deste artigo, a valorização do trabalho de grupo focal, aliado à produção de imagens e ao debate coletivo sobre as fotografias, que articulou elementos do encontro em grupos, conforme fala de uma estudante do $3^{\circ}$ ano do Ensino Médio: "Tu podes ver a opinião de outras pessoas, que pode ser igual ou diferente da tua, e eu acho que deveria ter mais vezes, mais aulas porque quatro encontros são muito pouco".

Todas estas discussões solicitam a nós, pesquisadores em Educação, seguir com investigações e estudos que exercitem o olhar sobre as imagens da (e na) escola, produzindo, com diferentes atores que constituem aquele espaço, discussões e criações sobre as múltiplas funções da escola na atualidade. Função de produção de gente, como também nos apresentaram os olhares dos estudantes, de humanidade, de respeito ao outro, de apresentação do mundo aos jovens e, juntamente a isto, a necessidade de articulação entre escola, mundo e vida. Enfim, que a escola seja efetivamente um lugar de possibilidade e atuação, de encontros que ela ainda promete - e parece fazer cumprir, mesmo que em meio a contradições - aos estudantes concluintes de Ensino Médio e Fundamental.

\section{REFERÊNCIAS}

1. ACHUTTI, Luiz Eduardo R. Imagem e fotografia: aprendendo a olhar. In: LEAL, Ondina F. (Org). Corpo e significado: ensaios de antropologia social. Porto Alegre: Editora da Universidade/UFRGS, 1995. p. 431-442.

2. AQUINO, Júlio Groppa. Indisciplina na escola: alternativas teóricas e práticas. São Paulo: Summus, 1996.

3. __ Do cotidiano escolar: ensaios sobre a ética e os seus avessos. São Paulo: Summus, 2000.

4. BANKS, Marcus. Dados visuais para pesquisa qualitativa. Tradução de José Fonseca. Porto Alegre: Artmed, 2009.

5. BANKS, Marcus. Visual methods in social research. London: Sage, 2001.

6. BARBOUR, Rosaline. Grupo focais. Porto Alegre: Artmed, 2009.

7. BARROSO, Geraldo. Crise da escola ou na escola? Uma análise da crise de sentido dos sistemas públicos de escolarização obrigatória. Revista Portuguesa de Educação, vol. 21, n 1, p. 33-58, 2008. 
8. BARTHES, Roland. O óbvio e o obtuso: ensaios críticos III. Rio de Janeiro: Nova Fronteira, 1990. SLAVUTZKY, Abrão (Orgs). A invenção da vida: arte e psicanálise. Porto Alegre: Artes e Ofícios, 2001. p. 22-30.

11. BENJAMIN, Walter. Magia e técnica, arte e política: ensaios sobre literatura e história da cultura. $7^{a}$ ed. São Paulo: Brasiliense, 1994. Educação, vol. 14, n 42, p. 521-604, set./dez. 2009. ultraliberal. Rio de Janeiro: Companhia de Freud, 2005.

14. DUBOIS, Phillipe. O ato fotográfico e outros ensaios. 14 ${ }^{\mathrm{a}}$ ed. Papirus: Campinas, 2012.

15. FISCHER, Rosa Maria Bueno. Trabalhar com Foucault: arqueologia de uma paixão. Belo Horizonte: Autêntica Editora, 2012. 1, p. 215-227, 2004. Brasileira de Educação, n² 20, p. 83-94, maio/ago. 2002.

18. FISCHMAN, Gustavo E.; SALES, Sandra R. Iconoclash: reflexões sobre a cultura visual e pesquisas em Educação. Educação, v. 37, n. 3, p. 423-432, 2014. http://dx.doi.org/10.15448/19812582.2014.3.18151.

19. FISCHMAN, Gustavo E.; DÍAZ, Victor H. Ensinar para qual América? Reflexões de professores iniciantes sobre suas escolhas profissionais e a crise econômica. E-curriculum, vol. 11, n² 2, p. 495514 , agosto 2013.

20. FISCHMAN, Gustavo E. Las fotos escolares como analisadores en la investigación educativa. Educação \& Realidade, vol. 31, n² 2, p. 79-94, jul./dez. 2006.

21. FOUCAULT, Michel. Microfísica do poder. Rio de Janeiro: Paz e Terra, 2015. 
22.

23.

24. FOUCAULT, Michel. História da sexualidade: a vontade de saber. Rio de Janeiro: Graal, 1988.

25. GATTI, Bernadete. Grupo focal na pesquisa em ciências sociais e humanas. Brasília: Líber Livro, 2005.

26. GIL, Antônio Carlos. Estudo de Caso: Fundamentação Científica. Subsídios para coleta e análise de dados. São Paulo: Atlas, 2009.

27. GUIRADO, Marlene. Psicologia Institucional: em busca da especificidade de atuação do psicólogo. In: Psicologia Institucional. São Paulo: EPU, 2004. p. 104-130.

28. 2010

29. KUBRUSLY, Cláudio. O que é fotografia? São Paulo: Brasiliense, 1991.

MASSCHELEIN, Jan; SIMONS, Maarten. Em defesa da escola: uma questão pública. $2^{\mathrm{a}}$ ed. Belo Horizonte: Autêntica Editora, 2014.

31. Ó, Jorge Ramos do; COSTA, Marisa Vorraber. Desafios à escola contemporânea: um diálogo. Educação \& Realidade, vol. 32, n² 2, p. 109-116, jul./dez. 2007.

32. PEIXOTO, Nelson Brissac. Ver o invisível - a ética das imagens. In: NOVAES, Adauto (Org). Ética. São Paulo: Companhia das Letras, Secretaria Municipal de Cultura, 1992. p. 301-320.

33. SIBILIA, Paula. Redes ou paredes: a escola em tempos de dispersão. Rio de Janeiro: Contraponto, 2012.

34. TORRE, Daniela; MURPHY, Joseph. A different lens: changing perspectives using Photo-Elicitation Interviews. Educational Policy Analysis Archives, vol. 23, $\mathrm{n}^{0}$ 111, p. 1-23, 2015. http://dx.doi.org/10.14507/epaa.v.23.2051.

35. TRAVERSINI, Clarice Salete. O desencaixe como forma de existência da escola contemporânea. In: $4^{\circ}$ SBECE - $1^{\circ}$ SIECE, 23 - 25/05/2011. Canoas: ULBRA, 2011. Disponível em: < 
https://pt.scribd.com/document/131427038/TRAVERSINI-Clarice-O-desencaixe-como-forma-deexistencia-da-escola-contemporanea>. Acesso em: 31/08/2017.

WANG, Caroline; YI, Wu Kun; TAO, Zhan Wen; CAROVANO, Kathrin. Photovoice as participatory health promotion strategy. Health Promotion International, vol. 13, no 1, p. 75-86, 1998.

37. WOODGATE, Roberta; ZURBA, Melanie; TENNENT, Pauline. Worth a thousand word? Advantages, challenges and opportunities in working with photovoice as qualitative research method with youth and their families. Forum: qualitative social research, vol. 18, $\mathrm{n}^{\circ}$ 1, 2017. Disponível em: <http://www.qualitative-research.net/index.php/fqs/article/view/2659/4045>. Acesso em: 11/09/2017.

38. WUNDER, Alik. Fotografias como exercícios de olhar. 2006. Trabalho apresentado no GT 16 Educação e Comunicação. Anais da 29a Reunião Científica da ANPEd. Caxambu, Outubro de 2006. Disponivel em: <29reuniao.anped.org.br/trabalhos/trabalho/GT16-2359--Int.pdf >. Acesso em: 14/06/2017.

\section{Suzana Feldens Schwertner}

Psicóloga. Doutora em Educação. Docente do curso de Psicologia da Univates. Docente do Mestrado em Ensino da Univates.

\section{Como citar este documento:}

SCHWERTNER, Suzana Feldens. Fotografias em discurso: as funções da escola em foco. Reflexão e Ação, Santa Cruz do Sul, v. 27, n. 1, dez. 2018. ISSN 1982-9949. Disponível em: <https://online.unisc.br/seer/index.php/reflex/article/view/10930>. Acesso em: doi:https://doi.org/10.17058/rea.v27i1.10930. 